\title{
Development of a Sensitive Diagnostic Device Based on Zeolitic Imidazolate Frameworks-8 Using Ferrocene-Graphene Oxide as Electroactive Indicator for Pseudomonas aeruginosa Detection
}

Saeed Shahrokhian+¥¥*, Saba Ranjbar ${ }^{+}$

${ }^{\dagger}$ Department of Chemistry and ${ }^{\ddagger}$ Institute for Nanoscience and Nanotechnology, Sharif University

of Technology, Azadi Avenue, Tehran 11155-9516, Iran

*E-mail: shahrokhian@sharif.edu.

Total number of pages: 18 (S1-S18)

Total number of Scheme: 1 (S1)

Total number of figures: 15 (S1-S15)

Total number of tables: $1(\mathrm{~S} 1)$ 

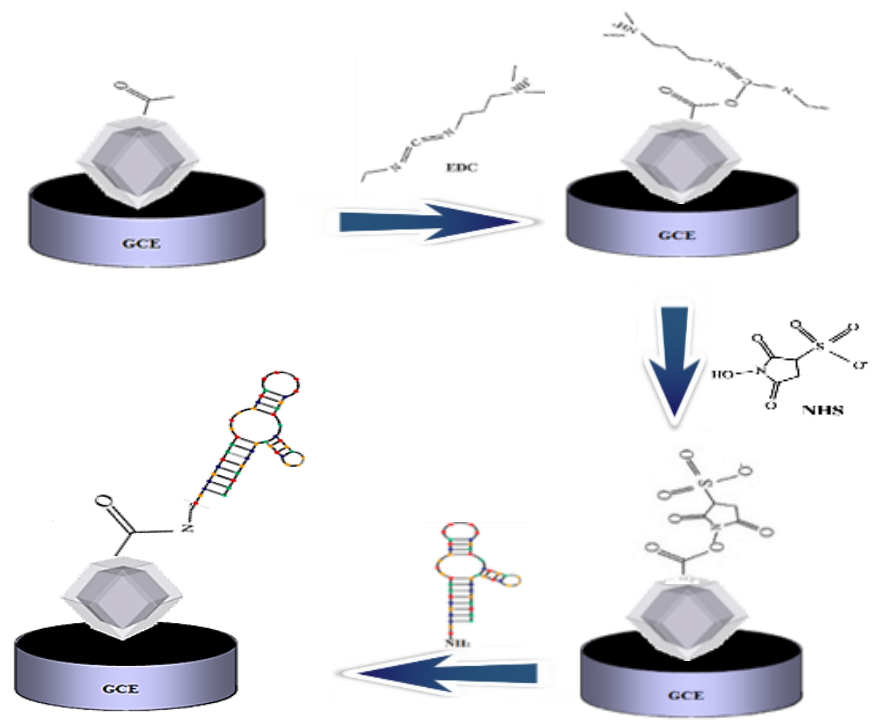

Scheme S1. Schematic illustration of interaction between HZIFs- 8 and amine modified aptamer with EDC-NHS as cross linking agent. 

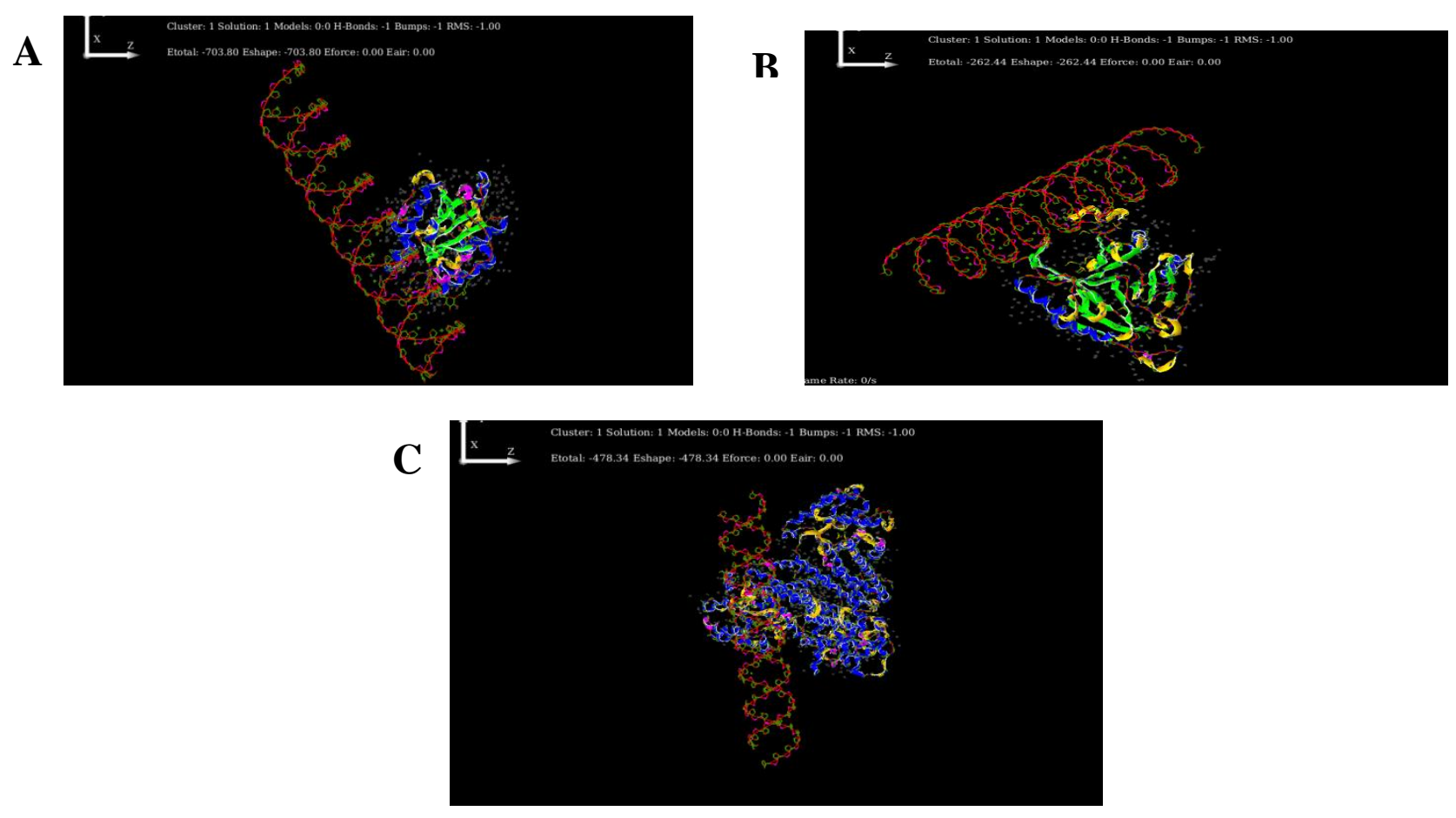

Figure S1. Interaction of aptamer with some $p$. aeruginosa specific epitopes simulated by HEX.8.0.0 software (A) PhzD protein, (B) protein PA1353 and (C) Protein PA2201. 


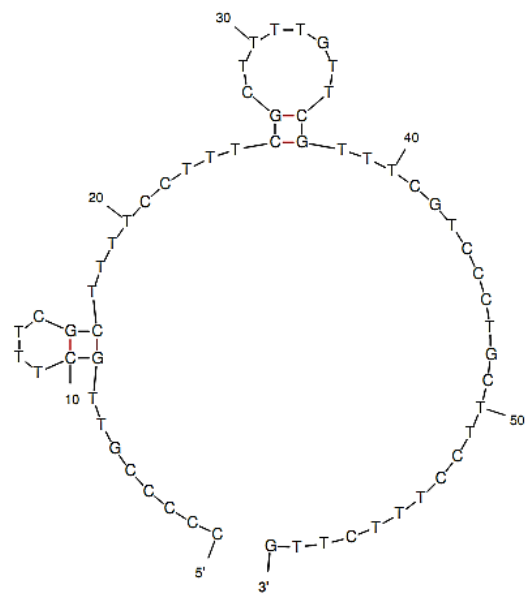

Figure S2. Secondary structure of p. aeruginosa DNA aptamer predicted by mfold program. 


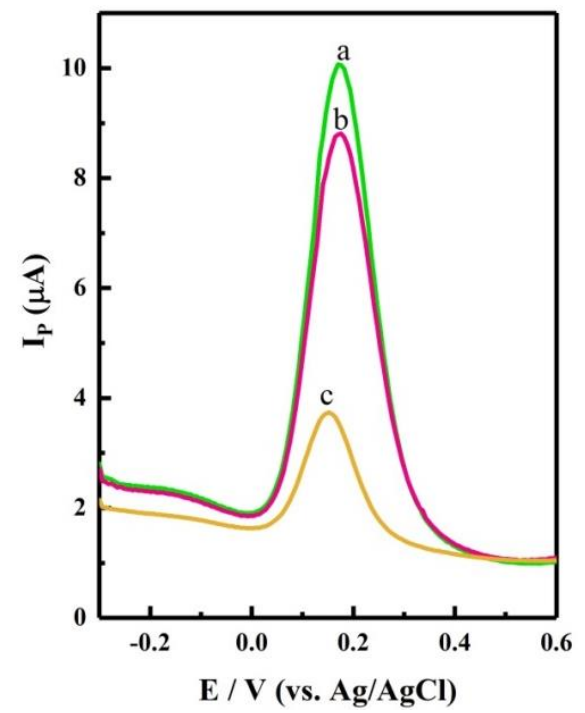

Figure S3. The DPV response of aptasensor incubated in (a) $2 \mathrm{mg} / \mathrm{mL}$ of Fc-GO for $60 \mathrm{~min}$, (b) Fc-GO (2 mg/mL, $60 \mathrm{~min})$ and immersed in PBS (0.1 M, pH = 7.4, $20 \mathrm{~min})$ and (c) Fc-GO (2 $\mathrm{mg} / \mathrm{mL}, 60 \mathrm{~min})$, immersed in $\mathrm{PBS}(0.1 \mathrm{M}, \mathrm{pH}=7.4,20 \mathrm{~min})$ and incubated in of p. aeruginosa $\left(1.2 \times 10^{5} \mathrm{CFU} \mathrm{mL}^{-1}, 20 \mathrm{~min}\right)$. 

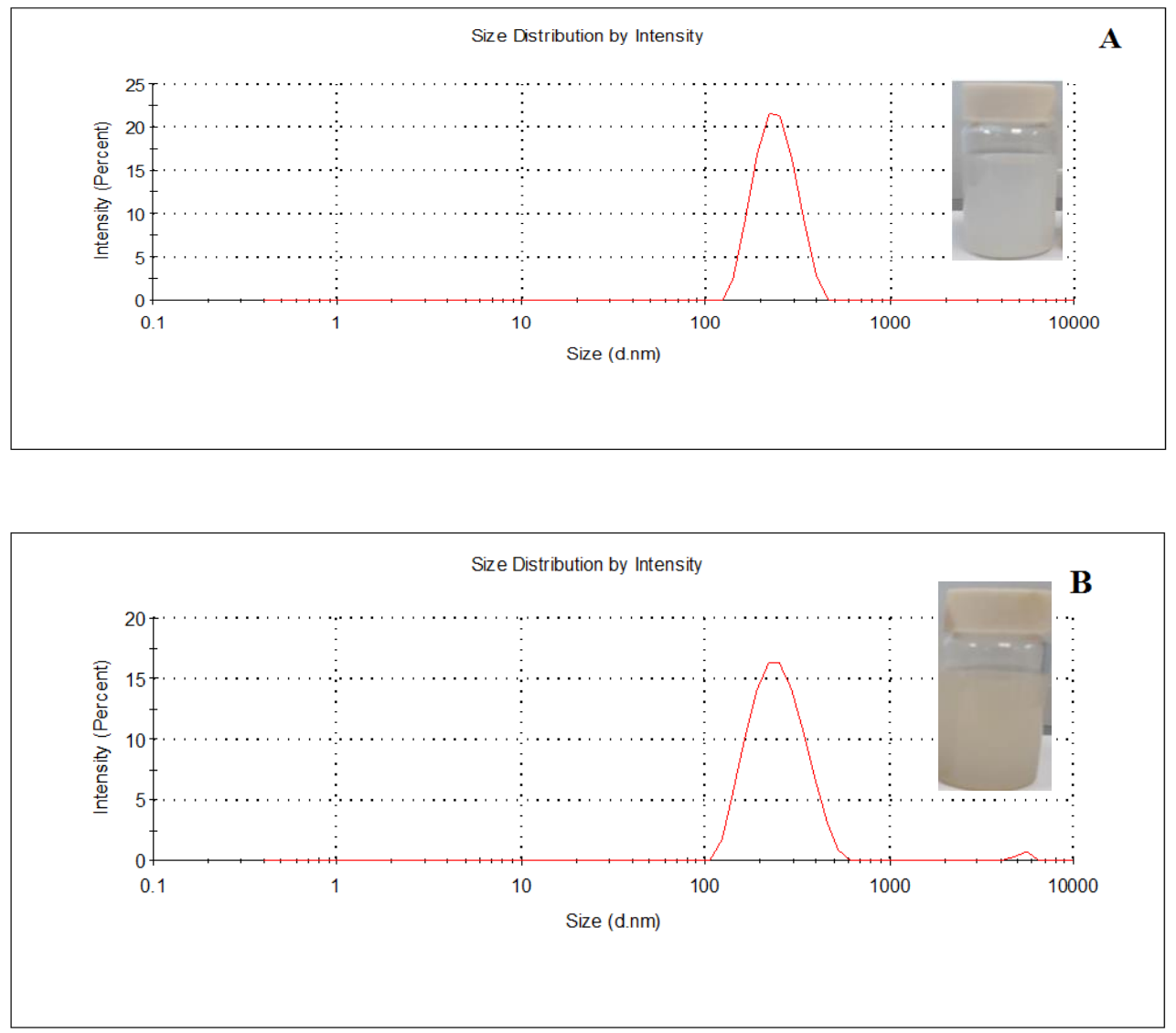

Figure S4. DLS analysis of (A) ZIFs-8 and (B) HZIFs-8. 

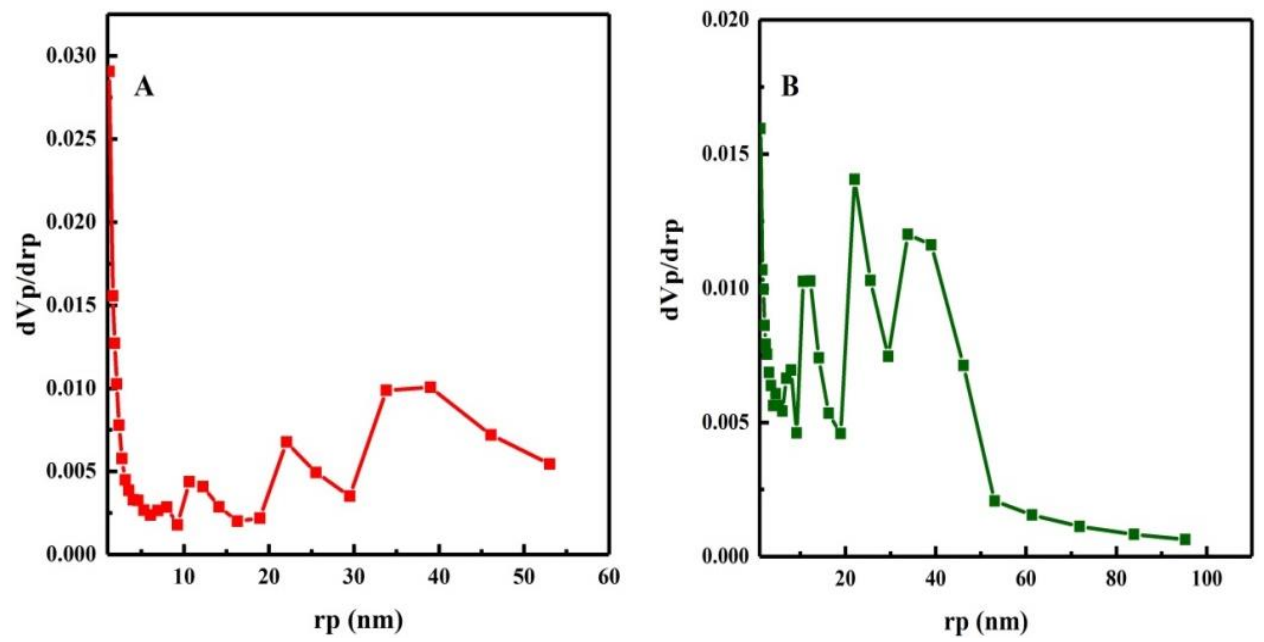

Figure S5. Pore size distribution curves of (A) ZIFs-8, and (B) HZIFs-8 calculated by Barrett-Joyner-Halenda (BJH) method. 

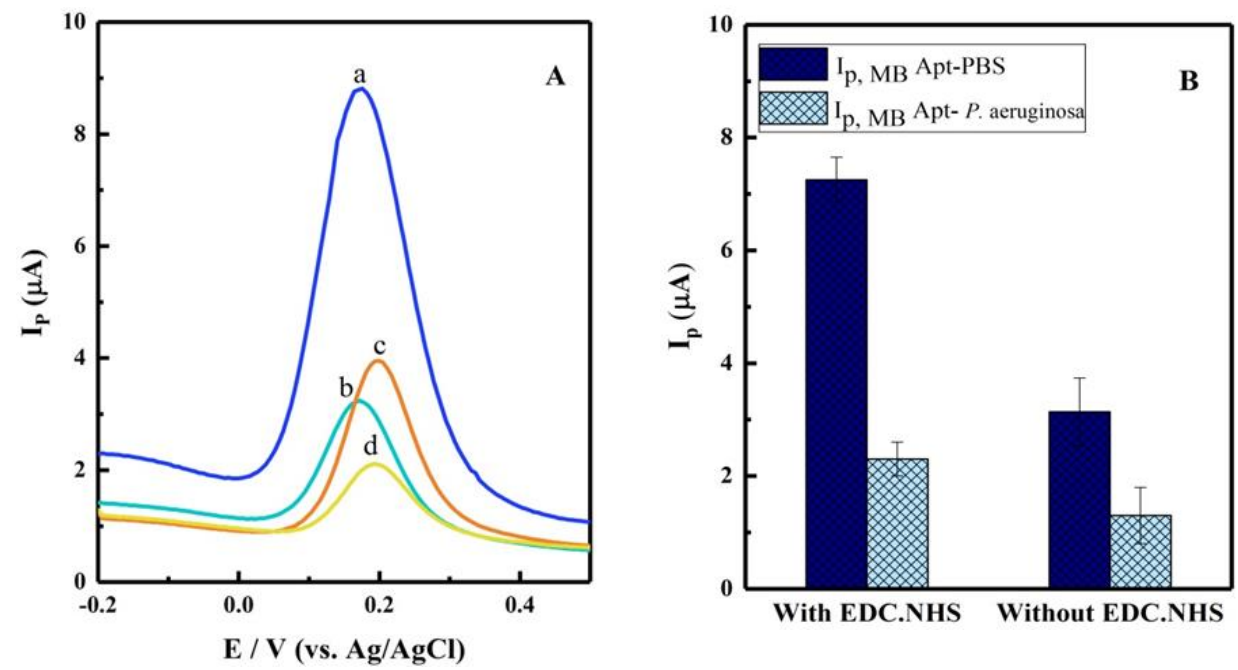

Figure S6. (A) DPV signal recorded in PBS $(0.1 \mathrm{M}, \mathrm{pH}=7.4$ ) for (a and b) Fc-GO/Apt/EDC-NHS/HZIFs8/GCE before and after incubation in $P$. aeruginosa $\left(1.2 \times 10^{5} \mathrm{CFU} \mathrm{mL}^{-1}, 20 \mathrm{~min}\right.$ ), (c and d) FcGO/Apt/HZIFs-8/GCE before and after incubation in $P$. aeruginosa $\left(1.2 \times 10^{5} \mathrm{CFU} \mathrm{mL}^{-1}, 20 \mathrm{~min}\right)$ and (B) bar chart of peak current change for Fc-GO at Apt/HZIFs-8/GCE, in presence and absence of EDC-NHS. 


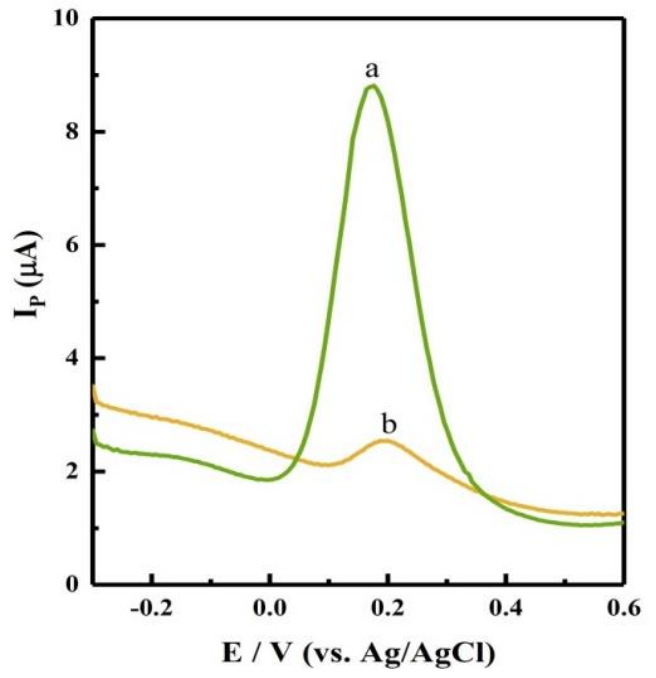

Figure S7. DPV signal recorded in PBS (0.1 M, pH = 7.4) for Apt/EDC-NHS/HZIF-8/GCE incubated in (a) Fc-GO and (b) Fc suspension ( $2 \mathrm{mg} / \mathrm{mL}, 60 \mathrm{~min}$ ). 


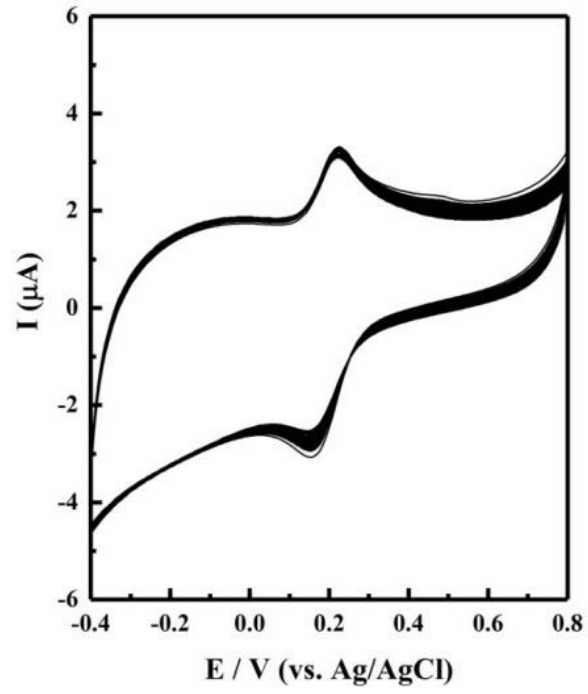

Figure S8. Cyclic voltammograms recorded in PBS (0.1 M, pH = 7.4) for Fc-GO/Apt/HZIFs8/GCE during 50 cycles (scan rate, $100 \mathrm{mVs}^{-1}$ ). 


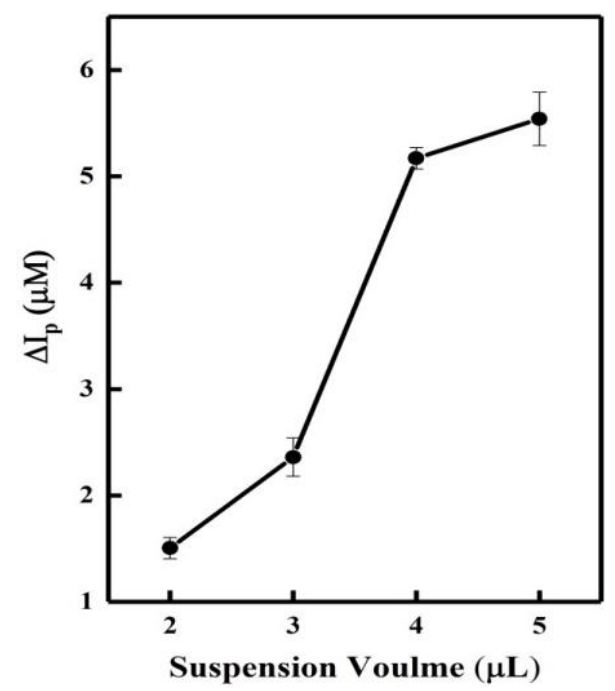

Figure S9. The plot of $\Delta \mathrm{I}_{\mathrm{p}, \mathrm{Fc}-\mathrm{GO}}$ obtained with DPV technique for Fc-GO (2 mg/mL, $\left.60 \mathrm{~min}\right)$ versus HZIFs-8 suspension volume in presence of $1.2 \times 10^{5} \mathrm{CFU} \mathrm{mL}^{-1}$ p. aeruginosa. 

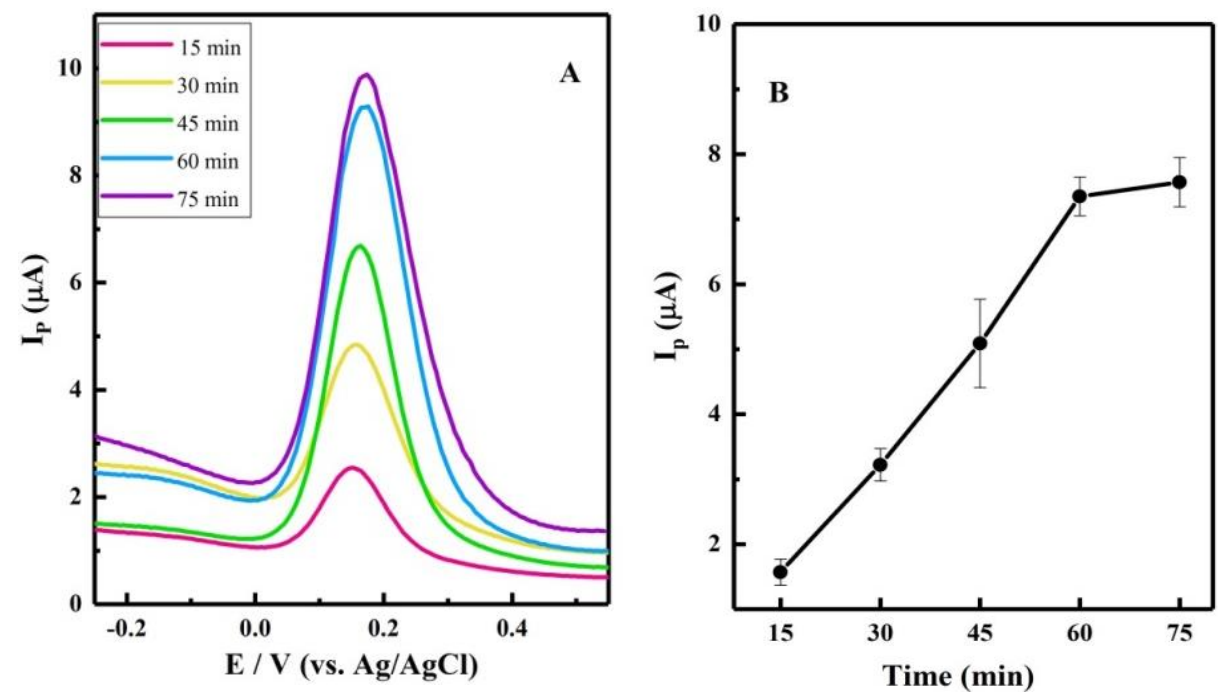

Figure S10. (A) DPV signal recorded in PBS (0.1 M, pH = 7.4) for aptasensor at various Fc-GO $(2 \mathrm{mg} / \mathrm{mL})$ incubation times and $(\mathrm{B})$ the plot of $\mathrm{I}_{\mathrm{p}, \mathrm{Fc}-\mathrm{GO}}$ versus $\mathrm{Fc}-\mathrm{GO}$ incubation time. 

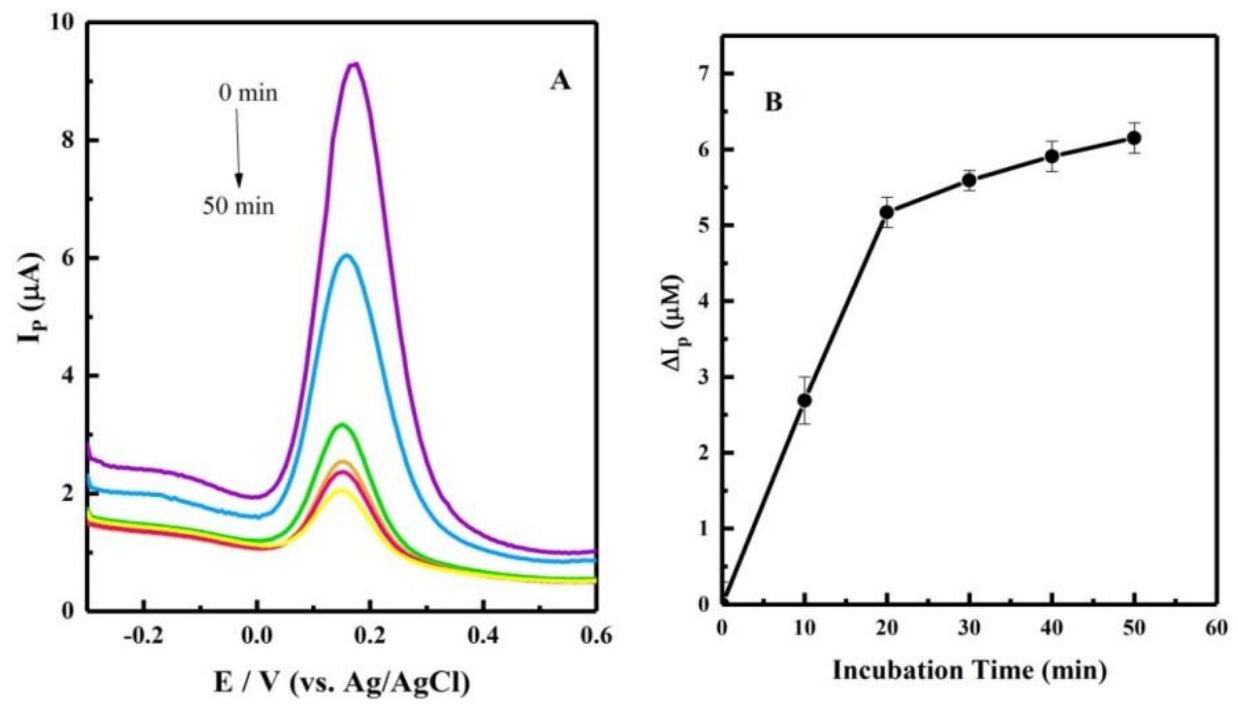

Figure S11. (A) DPV signal of Fc-GO $(2 \mathrm{mg} / \mathrm{mL}, 60 \mathrm{~min})$ recorded in PBS (0.1 M, $\mathrm{pH}=7.4$ ) for aptasensor in various $p$. aeruginosa incubation time (B) The plot of $\Delta \mathrm{I}_{\mathrm{p}, \mathrm{Fc}-\mathrm{GO}}$ versus $p$. aeruginosa $\left(1.2 \times 10^{5} \mathrm{CFU} \mathrm{mL}^{-1}\right)$ incubation time. 


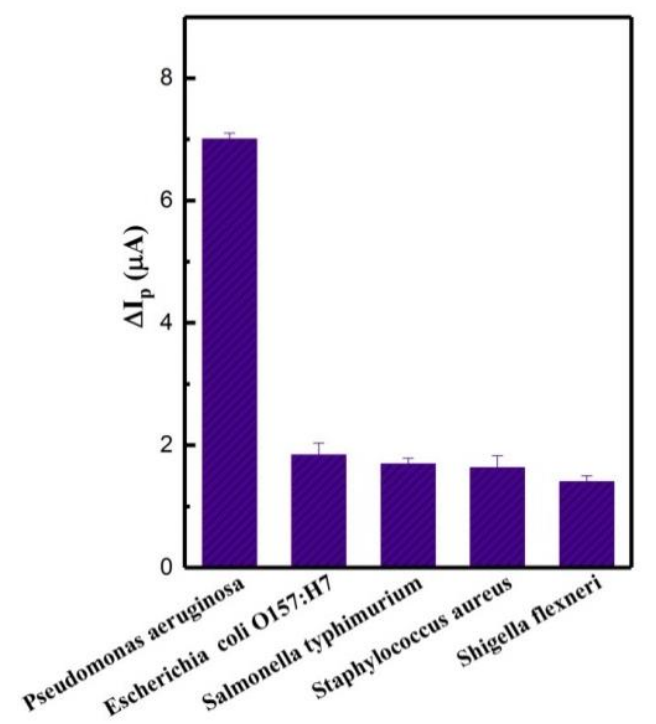

Figure S12. Evaluation the selectivity of proposed aptasensor for $p$. aeruginosa compared to the other bacteria strains $\left(10^{7} \mathrm{CFU} \mathrm{mL}^{-1}\right)$. 

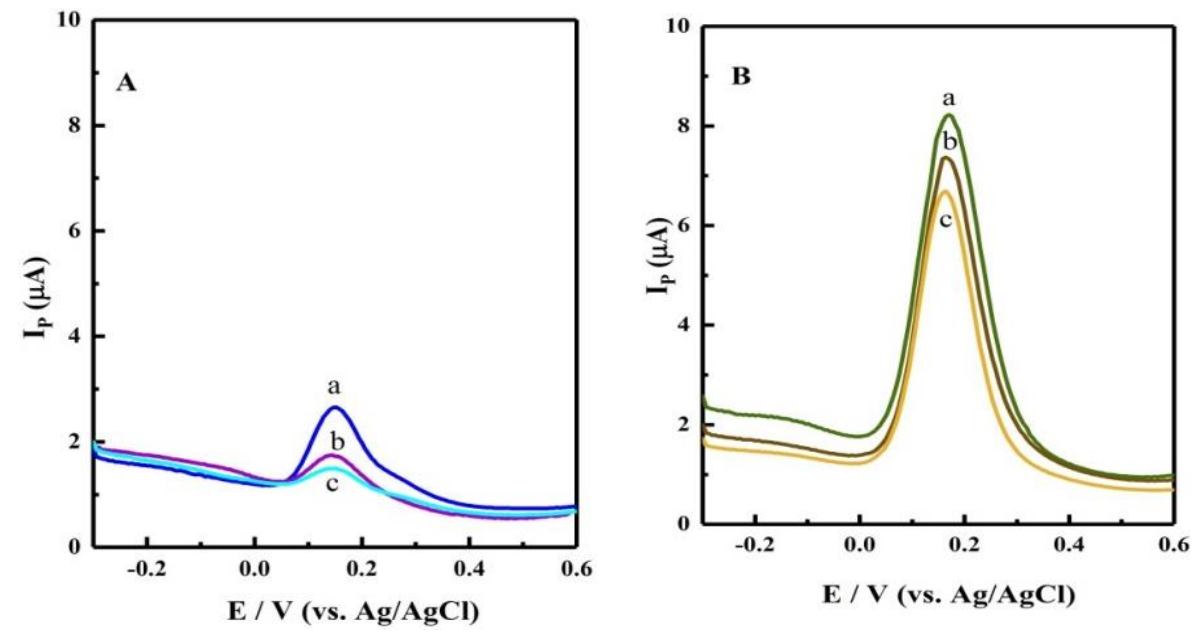

Figure S13. The DPV response of (A) HZIFs-8/GCE without aptamer modification and (B) HZIFs-8/GCE modified with E. coli O157:H7 specific aptamer in (a) $2 \mathrm{mg} / \mathrm{mL}$ of Fc-GO for 60 min, (b) Fc-GO (2 mg/mL, $60 \mathrm{~min})$ and immersed in PBS (0.1 M, pH = 7.4, $20 \mathrm{~min})$, and (c) Fc$\mathrm{GO}(2 \mathrm{mg} / \mathrm{mL}, 60 \mathrm{~min})$, immersed in $\mathrm{PBS}(0.1 \mathrm{M}, \mathrm{pH}=7.4,20 \mathrm{~min})$ and incubated in $p$. aeruginosa $\left(1.2 \times 10^{5} \mathrm{CFU} \mathrm{mL}^{-1}, 20 \mathrm{~min}\right)$. 


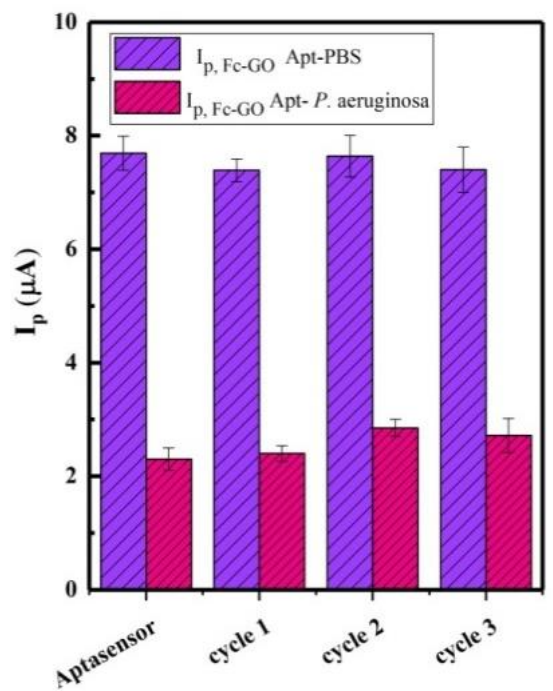

Figure S14. Bar chart for illustrate the regeneration of fabricated aptasensor in presence of $2 \mathrm{M}$ $\mathrm{NaCl}$ for $1.2 \times 10^{5} \mathrm{CFU} \mathrm{mL}^{-1}$ p. aeruginosa. 

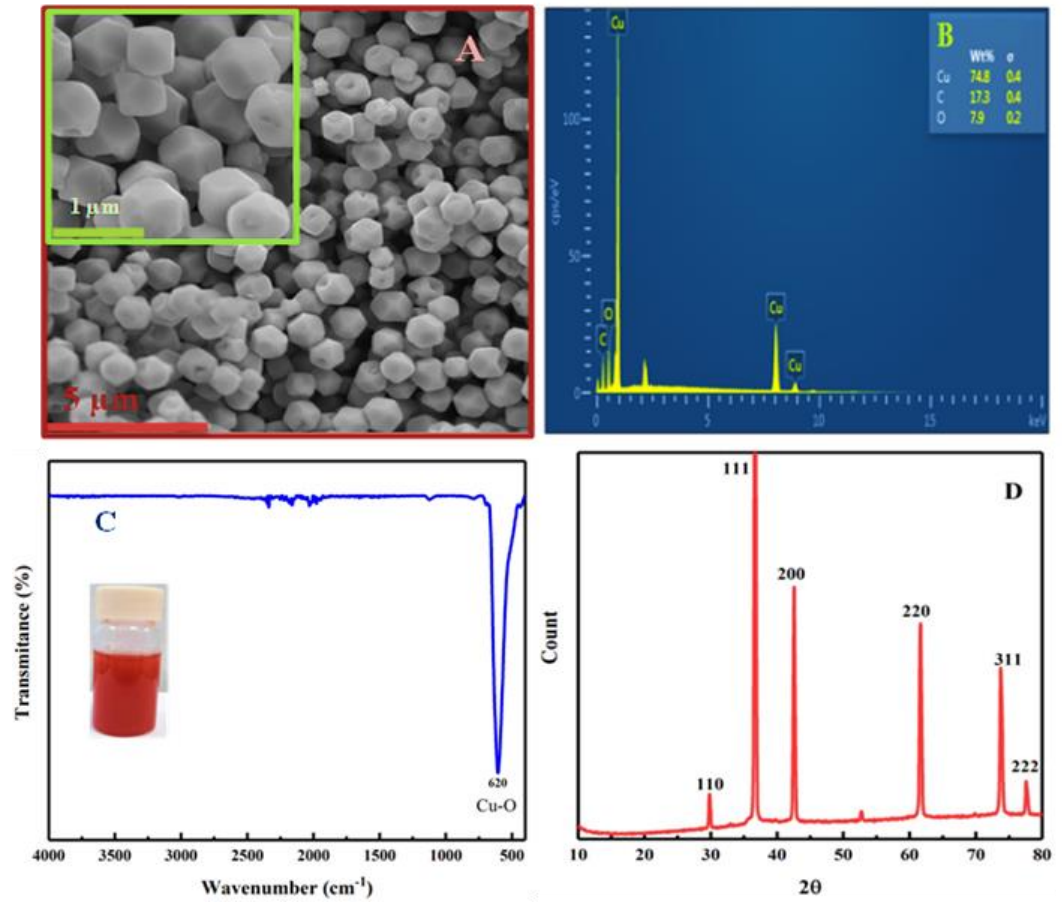

Figure S15. (A) FE-SEM, (B) EDS, (C) FT-IR and (D) XRD analysis of $\mathrm{Cu}_{2} \mathrm{O}$ particles as an antibacterial reagent. 
Table S1. Recovery tests for $p$. aeruginosa in human urine samples.

\begin{tabular}{|c|c|c|c|c|c|}
\hline No of samples & $\begin{array}{c}\text { Sample } \\
\text { Human urine }\end{array}$ & $\begin{array}{c}\text { Spiked } \\
\left(\mathrm{CFU} \mathrm{mL} \mathbf{~}^{-1}\right)\end{array}$ & $\begin{array}{c}\text { Found } \\
\left(\mathrm{CFU} \mathrm{mL} \mathbf{~}^{-1}\right)^{\mathrm{a}}\end{array}$ & $\begin{array}{c}\text { RSD (\%) } \\
\qquad(n=3)\end{array}$ & $\begin{array}{c}\text { Recovery } \\
(\%)\end{array}$ \\
\hline \multirow{3}{*}{1} & \multirow{3}{*}{ Woman (25-35 years old) } & 0.0 & 0.0 & - & - \\
\hline & & $1.2 \times 10^{3}$ & $1.3 \times 10^{3}$ & 5.84 & 108.33 \\
\hline & & $1.2 \times 10^{5}$ & $1.28 \times 10^{5}$ & 2.76 & 106.67 \\
\hline \multirow{3}{*}{2} & \multirow{3}{*}{ Woman (25-35 years old) } & 0.0 & 0.0 & - & - \\
\hline & & $1.2 \times 10^{3}$ & $9.75 \times 10^{2}$ & 7.53 & 81.25 \\
\hline & & $1.2 \times 10^{5}$ & $1.17 \times 10^{5}$ & 6.40 & 97.50 \\
\hline \multirow{3}{*}{3} & \multirow{3}{*}{ Man (25-35 years old) } & 0.0 & 0.0 & - & - \\
\hline & & $1.2 \times 10^{3}$ & $1.41 \times 10^{3}$ & 3.95 & 117.5 \\
\hline & & $1.2 \times 10^{5}$ & $1.04 \times 10^{5}$ & 2.86 & 86.67 \\
\hline \multirow{3}{*}{4} & \multirow{3}{*}{ Man (25-35 years old) } & 0.0 & 0.0 & - & - \\
\hline & & $1.2 \times 10^{3}$ & $1.42 \times 10^{3}$ & 2.3 & 118.33 \\
\hline & & $1.2 \times 10^{5}$ & $1.10 \times 10^{5}$ & 5.12 & 91.67 \\
\hline
\end{tabular}

${ }^{a}$ Average of three replicate measurements 